\title{
In Vitro Evaluation and Molecular Docking Studies of Aryl- Substituted Imidazoles against Leishmania Amazonensis
}

\author{
Julio Alberto Rojas Vargas ${ }^{1^{*}}$ (D), América García López ${ }^{1}$ (D), Aliesky Ramírez \\ Vargas $^{2}$, Lianet Monzote Fidalgo 3 (iD and Matheus Froeyen ${ }^{4}$ (iD)
}

${ }^{1}$ Chemistry Department, Faculty of Natural and Exact Sciences, Universidad de Oriente, Santiago de Cuba, Cuba

${ }^{2}$ Toxicology Lab, Plant Health Laboratory of Las Tunas, Las Tunas, Cuba

${ }^{3}$ Parasitology Department, Instituteof Tropical Medicine "Pedro Kouri", Havana, Cuba

${ }^{4}$ Department of Pharmaceutical and Pharmacological Sciences, Rega Institute for Medical Research, Medicinal Chemistry, KU Leuven, Belgium

*Corresponding author: Julio Alberto Rojas Vargas, Chemistry Department, Faculty of Natural and Exact Sciences, Universidad de Oriente, Santiago de Cuba, Cuba

\begin{abstract}
Leishmaniasis is a disease caused by the protozoan Leishmania that is considered one of the causes of death from parasitic infection worldwide. Looking for the right chemotherapy against leishmaniasis has been difficult because of the high toxicity of the most effective drugs. This disease is considered among the 13 unattended diseases worldwide according to the World Health Organization (WHO). In the present work, the leishmanicidal activity against $L$. amazonensis promastigote and cytotoxicity of 9 aryl-substituted imidazoles were evaluated. In vitro antileishmanial results indicated that the ligand 1,2 and 7 exhibited strong activity against $L$. amazonensis promastigote, but only the compound 1 and 4 showed agood selectivity and cytotoxicity against the parasite. According to the results of the molecular docking, the aromatic substituents have mainly stabilizing hydrophobic interactions with the enzymatic matrix, which shows the probability that the protein trypanothione reductase is the therapeutic target of these compounds as possible antileishmanial drugs.
\end{abstract}

\section{Keywords}

Aryl-substituted imidazoles, Leishmania amazonensis, Antileishmanial activity, Molecular docking

\section{Introduction}

Leishmaniasis is a neglected disease caused by an intracellular protozoon transmitted by the bite of insects of the Phlebotominae subfamily (sandflies). Over 20 Leishmania species are known to be infective to humans. There are three main types of leishmaniasis: the most common clinical form is the cutaneous leishmaniasis $(\mathrm{CL})$, whereas, the visceral leishmaniasis (VL) is more severe and often fatal if not treated. Moreover, the mucosal/mucocutaneous (MCL) has a chronic progression which may lead to deformities and long-term effects. This disease is among the endemics considered a priority in the world, being cited in 98 countries, affecting around 2 million people per year, with 350 million people being exposed to infection [1].

Only few drugs are available for the treatment of different forms of leishmaniasis. Pentavalent antimonials are of high cost and have severe side-effects [2]. These compounds are a first-line drug treatment for leishmaniasis, including sodium stibogluconate and meglumine antimoniate. Drugs, such as miltefosine, liposomal amphotericin $B$, pentamidine and paromomycin, have also been used to treat this disease [3]. Due to the problems associated with the severe adverse effects, high cost, drug resistance and the limited progress in developing a vaccine against human leishmaniasis, development of new drugs is highly required.

Nitrogen-containing heterocycles are ubiquitous

Citation: Vargas JAR, López AG, Vargas AR, Fidalgo LM, Froeyen M (2021) In Vitro Evaluation and Molecular Docking Studies of Aryl-Substituted Imidazoles against Leishmania Amazonensis. Int J Trop Dis 4:050. doi.org/10.23937/2643-461X/1710050

Accepted: July 21, 2021; Published: July 23, 2021

Copyright: (c) 2021 Vargas JAR, et al. This is an open-access article distributed under the terms of the Creative Commons Attribution License, which permits unrestricted use, distribution, and reproduction in any medium, provided the original author and source are credited. 
in numerous biomolecules. The imidazoles are a vital class of compounds due to their prevalence in several biomolecules such as histidine, purines and natural products (alkaloids) [4,5]. These are considered as beneficial structural motifs by its wide range of applications, specifically those highly substituted imidazoles exhibit potent biological properties like antibacterial [6], anti-inflammatory [7,8], anticancer activities and work as neurogenic agents $[9,10]$. Drugs like fenflumizole ${ }^{\circledR}$, losarton ${ }^{\circledR}$ and eprosartan ${ }^{\circledR}$ are some of the marketed drugs as substituted Imidazoles $[9,10]$.

According to Rossi, et al. [11] several substituted imidazole with antileishmanial activity have been found. One tetrasubstituted imidazole has been reported as potential antileishmanial agent described by Prajapati and coworkers in 2015 [12]. They used virtual screening, molecular docking, ADMET, QikProp, MM-GBSA and molecular dynamics of 5-nitroimidazole analogues and concluded that the ethyl 2-acetyl-5-[4butyl-2-(3-hydroxypentyl)-5-nitro-1H-imidazol-1-yl] pent-2-enoate has the great potential to develop an antileishmanial drug to kill $L$. donovani parasites. Other substituted imidazoles reported by Srinivas, et al. [13] in 2009 with antileishmanial activity against $L$. donovani. In addition, other recent studies reported by Martin, et al. [14] demonstrated the potential of imidazole salts as antileishmanial agents against promastigotes of $L$. amazonensis.

In the present study, we describe the leishmanicidal activity of different aryl-substituted imidazoles against L. amazonensis promastigote, as well as the application of the molecular docking technique, in order to explore the possible binding mode of aryl-substituted imidazoles to different targets from $L$. amazonensis. The compounds have already been reported to exhibit prominent antileishmanial activity against amastigotes of L. infantum (causal agent of VL) [15], but have not previously been tested against $C L$ species such as $L$. amazonensis.

\section{Materials and Methods}

\section{Compounds}

The chemical structures of nine aryl-substituted imidazoles are shown in Figure 1. The aryl-substituted imidazoles were obtainedby reaction ofaromatic aldehydes, primary amines, benzils, and ammonium acetate reported by our group in previous work [15]. The compound 1-benzyl-2-(3-nitrophenyl)-4,5diphenyl-1H-imidazole (3), was synthesized following the same methodology reported in our previous article [15] and was confirmed through its physical and spectral properties.Melting points were determined in open capillaries using a Digital Melting Point apparatus WRS2A (Jiangsu Zhengji Instruments Co., Ltd, China). ${ }^{1} \mathrm{H}-\mathrm{NMR}$ and ${ }^{13} \mathrm{C}-\mathrm{NMR}$ spectra were recorded with a Bruker DRX500 spectrometer (Bruker, United Kingdom) obtained in DMSO- $d_{6}$. The FT-IR spectra were recorded on a FTIR Infrared spectrometer (Shimadzu Corporation, Japan) in $\operatorname{KBr}\left(v_{\max }\right.$ in $\left.\mathrm{cm}^{-1}\right)$.

Spectral data results for compound 3: 1-benzyl-2(3-nitrophenyl)-4,5-diphenyl-1H-imidazole.MW: 431.16 mp: $150-152^{\circ} \mathrm{C}$ (Reported: $151-153^{\circ} \mathrm{C}$ ) [16]. FT-IR (KBr, $\left.\mathrm{cm}^{-1}\right): v_{\max } 3056\left(\mathrm{C}=\mathrm{C}_{\text {arom }}\right), 1685(\mathrm{C}=\mathrm{N}), 1524(\mathrm{~N}-\mathrm{O}), 1457$ y $1500\left(\mathrm{C}=\mathrm{C}_{\text {arom }}\right), 1340\left(\mathrm{C}-\mathrm{NO}_{2}\right) \cdot \delta_{\max } 853\left(\mathrm{C}-\mathrm{N}_{\mathrm{Ar}-\mathrm{NO} 2}\right), 710$ y $810\left(\mathrm{C}-\mathrm{H}_{\text {m-sust }}\right) ;{ }^{1} \mathrm{H}-\mathrm{NMR}\left(600 \mathrm{MHz}\right.$, DMSO- $\left.d_{6}\right): \delta \mathrm{ppm}$ $5.13\left(\mathrm{~s}, 2 \mathrm{H}, \mathrm{CH}_{2}\right), 6.78-8.12(\mathrm{~m}, 19 \mathrm{H}, \mathrm{Ar}-\mathrm{H}) ;{ }^{13} \mathrm{C}-\mathrm{NMR}$ $\left(150 \mathrm{MHz}, \mathrm{DMSO}-d_{6}\right): \delta \mathrm{ppm} 51.88\left(\mathrm{CH}_{2}\right), 122.0,123.9$, $127.43,128.04,128.29,129.07,129.20,133.64,134.3$, 135.36, 136.93, 137.3, 144.4, 147,8, 148.4, 150.9, 153.7 $\left(\mathrm{C}_{\text {arom }}\right)$; Mass spectrum (ES+): $\mathrm{M}\left(\mathrm{C}_{28} \mathrm{H}_{21} \mathrm{~N}_{3} \mathrm{O}_{2}\right)$ calculated:

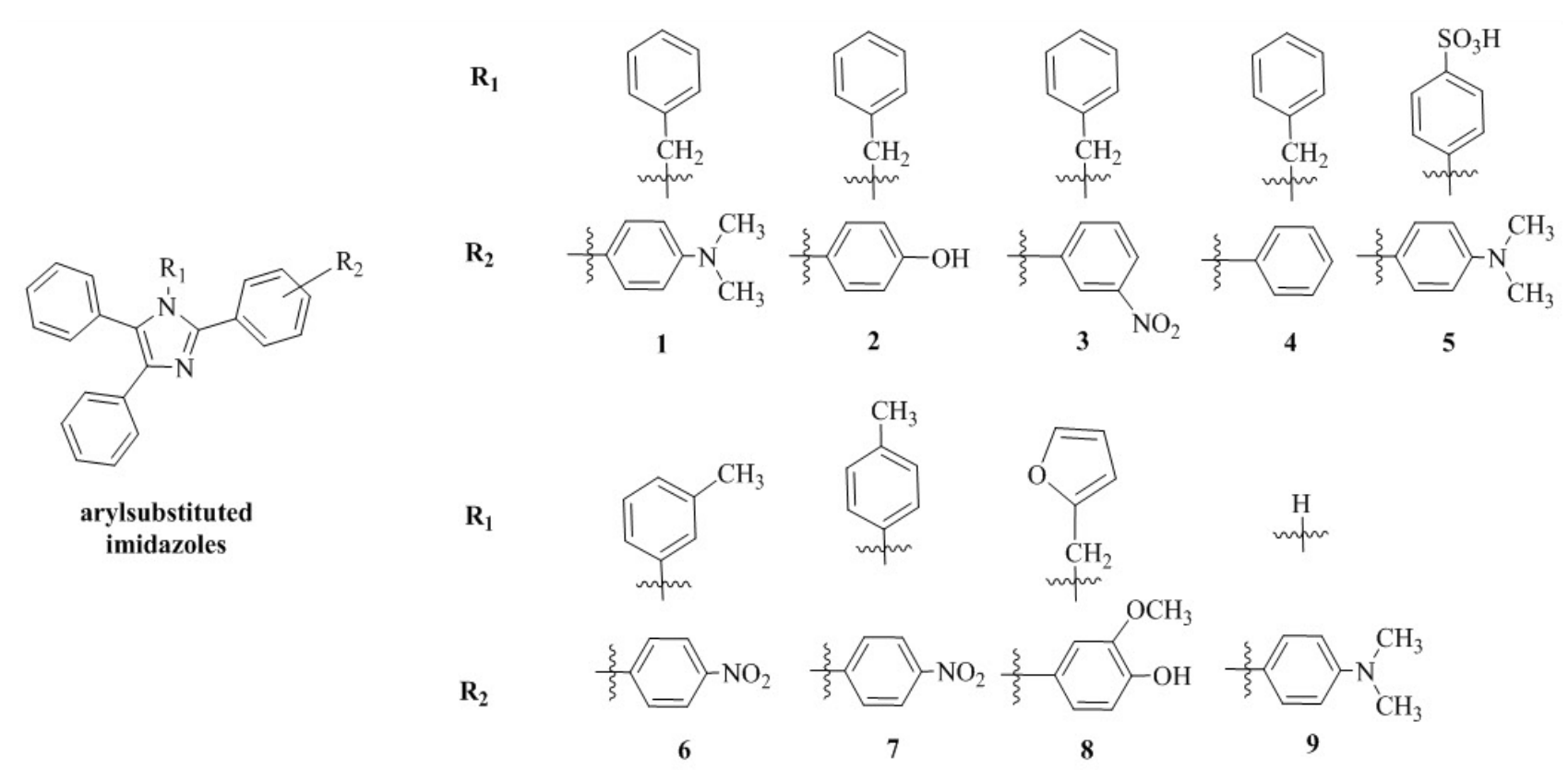

Figure 1: Chemical structures of aryl-substituted imidazole. 
431.50 experimental: $431.6[\mathrm{M}+\mathrm{H}]^{+}, 386.15,309.14$, 219.9 .

The nine compounds were dissolved in dimethylsulfoxide (DMSO, BDH, Poole, England) at a concentration of $20 \pm 0.1 \mathrm{mg} / \mathrm{mL}$ in the stocks solutions for the biological studies.

\section{Antileishmanial assay}

Microorganism: Parasite strains were: $L$. amazonensis MHOM/BR/77/LTB0016 maintained in the culture collection of the Institute of Tropical Medicine Pedro Kourí, Havana, Cuba.

Antipromastigotes assay: In the first well of a 96-wells microplate with conical bottom (Greiner Bioone, Germany), $2 \mu \mathrm{L}$ of compounds extract was added to $98 \mu \mathrm{L}$ of Schneider's medium (SIGMA, St. Louis, MO, USA) supplemented with $10 \%$ heat-inactivated fetal bovine serum (SIGMA) and penicillin-streptomycin as antibiotics (SIGMA); while $50 \mu \mathrm{L}$ of medium were distributed in the other wells. Then, serial dilutions 1:2 were carried out to obtain final concentrations between 6.25 and $200 \mu \mathrm{g} / \mathrm{mL}$. Afterwards, $50 \mu \mathrm{L}$ of promastigotes were added at $4 \times 10^{5}$ parasite $/ \mathrm{mL}$ in logarithmic phase. Microplates were sealed with parafilm and incubated at $26^{\circ} \mathrm{C}$ for 72 hours. After incubation, $20 \mu \mathrm{L}$ of a solution of 3-[4,5-dimethylthiazol-2-yl]-2,5-diphenyltetrazolium bromide (MTT; SIGMA) at $5 \mathrm{mg} / \mathrm{mL}$ was added in each well. An additional incubation of 4 hours was performed, the supernatant was eliminated, and the formazan crystals were dissolved with $100 \mu \mathrm{L}$ of DMSO. Finally, the microplate was read in an ELISA microplate reader (Sirio S Reader, 2.4-0, Italy) at $540 \mathrm{~nm}$ and 620 $\mathrm{nm}$ as reference wavelength [17]. The median inhibitory concentration $\left(\mathrm{IC}_{50}\right)$ was determined by dose-response linear regression analysis. Each experiment was performed in duplicate and the results were expressed as the mean \pm standard deviation.

\section{Cytotoxicity assay}

Peritoneal macrophages: Resident macrophages from the peritoneal cavity were collected and washed with cold RPMI 1640 medium (SIGMA), supplemented with antibiotics (penicillin $200 \mathrm{IU}$, streptomycin $200 \mu \mathrm{g} /$ $\mathrm{mL}$ ). Then, $1-3 \times 10^{6}$ macrophages $/ \mathrm{mL}$ were seeded in 96-well plates with conical bottom (Greiner Bio-one, Germany) and incubated for 2 hours at $37^{\circ} \mathrm{C}$ and $5 \% \mathrm{CO}_{2}$ atmosphere. The non-adherent cells were removed by washing with phosphate buffer solution. Subsequently, RPMI medium and compounds at the tested concentrations $(6.25-200 \mu \mathrm{g} / \mathrm{mL})$ were added per well. The plates were incubated for 72 hours under the same conditions and macrophages treated with DMSO were included as control. The cellular viability was determined by colorimetric assay with $15 \mu \mathrm{L}$ MTT, solution added per well. The median cytotoxic concentration $\left(\mathrm{CC}_{50}\right)$ was determined by dose-response linear regression analysis. Each experiment was performed in duplicated and the results were expressed as the mean \pm standard deviation.

\section{Selectivity index calculation}

The selectivity index (SI) was calculated using the $\mathrm{IC}_{50}$ (for protozoan) and $\mathrm{CC}_{50}$ (for macrophages) values obtained from each in-vitro assay [18], determined by the following Eq (1):

$$
\mathrm{SI}=\frac{\mathrm{CC}_{50} \text { in cell }}{\mathrm{IC}_{50} \text { against parasite }}
$$

where $\mathrm{CC}_{50}$ is the $50 \%$ cytotoxicity concentration. Potential products are those that show an $\mathrm{IC}_{50}<10$ $\mu \mathrm{M}$ [19] and a SI > 5 [20] according to international criterions.

\section{Molecular docking studies}

The molecular modelling was performed using the high-performance computing capabilities of the cluster of the Universidad de Oriente, Cuba (HPC-UO) (https:// portal.uo.hpc.cu/website/). Molecular docking is one of the main methods of structure-based drug design (SBDD) molecular modeling, providing significant contributions in the discovery and optimization phases of leading compounds. Molecular docking studies were implemented in order to compare the interaction of the aryl-substituted imidazoles at the molecular level with different enzymes reported for the specie $L$. amazonenzis.

Ligands preparation: The three-dimensional geometries of the aryl-substituted imidazoles were drawn in ChemDraw Professional v.17.1.0.105 [21]. The structures were imported to Chem3D v.17.1.0.105 [21] and subjected to molecular energy minimization using the AM1 semiempirical method included in Chem3D.

Proteins preparation: The docking process was performed with the crystallographic protein structures downloaded from the RCSB Protein Data Bank (PDB). For the protein Arginase-I (Argl), we used a previously described model of $L$. amazonensis arginase based on rat liver arginase complexed with $\mathrm{AOH}((\mathrm{S})$-2-amino7oxoheptanoic acid) (PDB, ID code 1T5F) [22,23]. The enzyme trypanothione reductase (TryR) from $L$. infantum (PDB ID: 2JK6), TryR is a flavoprotein disulfide reductase dependent on NAPDH, and is found only in parasites of the Trypanosomatidae family. It is present in both $L$. infantum and $L$. amazonensis according to reference [24]. The nucleoside diphosphate kinase $b$ (NDKb) from L. major (PDB ID: $3 N G U$ ) is a ubiquitous and conserved enzyme that plays a central role in the maintenance of intracellular nucleoside triphosphate (NTP) levels, and is also involved in the regulation of gene expression in mammalian cells, bacterial pathogenesis and parasite housekeeping [25]. These particular characteristics have made NDKs promising 
targets for the design and discovery of antiparasitic drugs, including antileishmanial agents.

The program AutoDock (v.4.2) was employed to perform docking experiments [26], keeping the protein fixed and allowing freely rotatable bonds for the ligands. The grid box was centered around the region of interest (active site) at the center-of mass of DHH ((S)-2amino-7,7-dihydroxyheptanoic acid), ADP (adenosine5 '-diphosphate) and FAD (flavin-adenine dinucleotide) three-dimensional coordinates retrieved from PDB ID: $1 T 5 F, 3 N G U$ and 2JK6, respectively (Table 1). The Lamarckian Genetic Algorithm (LGA) implemented in the AutoDock program was applied using default parameters. The selection of docking ligand binding poses was based on the ranking of the fifty ligand conformational clusters and their respective binding energy values.

\section{Identification of binding site residues}

The binding site for proteins was identified from the analysis of the structures 1T5F, 2JK6 and 3NGU available in the RCSB Protein Data Bank. The active site of Arginase I (PDB ID:1T5F) involves the amino acids Ser137, Glu186, Asn130, Asp183, Asp128, His126, Asp124, Asp232, Asp234, Glu277 and His101 [23]. In Trypanothione Reductase (PDB ID: 2JK6) the active site residues are the amino acids Lys60, lle199, Tyr198, Cys57, Arg287, Thr51, Pro336, Thr335, Ser14, Asp327, Thr160, Ala46, Asp35, Arg290 and Leu294 [27]. The Nucleoside Diphosphate Kinase b (PDB ID: 3NGU) active

Table 1: Grid box parameters selected for the target enzymes.

\begin{tabular}{|c|c|c|c|c|c|}
\hline \multirow{2}{*}{$\begin{array}{l}\text { PDB ID (Resolution) } \\
\text { 1T5F (2.20 A) }\end{array}$} & \multirow{2}{*}{$\begin{array}{l}\text { Organism } \\
\text { Rattus novergicus }\end{array}$} & \multirow{2}{*}{$\begin{array}{l}\text { Enzyme } \\
\text { Argl } \\
\end{array}$} & \multicolumn{3}{|c|}{$\begin{array}{l}x, y, z \\
\text { coordinates of left of box }\end{array}$} \\
\hline & & & 88.57 & 43.842 & -6.292 \\
\hline 2JK6 (2.95 Å) & L. infantum & TryR & 30.449 & 47.483 & -4.312 \\
\hline 3NGU (2.29 A) & L. major & $N D K b$ & -15.885 & -9.192 & -5.732 \\
\hline
\end{tabular}<smiles>O=C(NCc1ccc2ncccc2c1)c1cnn(-c2ncc3c(n2)-c2ccccc2CCC3)c1C1CC1</smiles>

(Trypanothione Reductase)<smiles>Cc1cc(NNC(N)=S)n2nc(C(F)(F)F)nc2n1</smiles>

(Arginase I)<smiles>CCN(CC)CCNC(=O)c1c(C)[nH]c(/C=C2\C(=O)Nc3ccc(Cl)cc32)c1C</smiles>

(nucleoside diphosphatase kinase b) 
site is formed by Lys11, Tyr51, Leu54, Phe59, Leu63, Tyr66, Arg87, Thr93, Arg104, Val111, Gly112, Asn114, Gly118 and Asp120 [28].

\section{Docking validation}

To check the docking procedure and given the similar structure (imidazole and triazole rings) between the compounds here reported, we choose three known inhibitors reported. Compound ZINC12151998 (5-cyclopropyl-1- (6,7-dihydro-5H-benzo [6,7] cyclohepta [1,2-d] pyrimidin-2-yl) -N- (quinolin-6ylmethyl) - 1H-pyrazole-4-carboxamide) proposed by Martinez, et al. [29] as a Trypanothione Reductase inhibitor, compound 2 - (5-methyl-2- (trifluoromethyl) - [1,2,4] triazolo [1,5-a] pyrimidin-7-yl) hydrazine-1carbothioamide (compound 30) reported as Arginase I inhibitor by Da Silva, et al. [30] and compound (Z)-5-((5-chloro-2-oxoindolin-3-ylidene) methyl)-N(2-(diethylamino)ethyl)-2,4-dimethyl-1H-pyrrole-3carboxa-mide (SU11652) nucleoside diphosphatase kinase (NDK) inhibitor reported by Vieira, et al. [31], were rebuilt and redocked (Figure 2).

\section{Results and Discussion}

\section{Antipromastigote leishmanicidal activity}

Infections caused by parasites are today a serious problem in the health systems of many countries. Among these parasitic infections, leishmaniasis (caused by Leishmania spp.), Chagas disease (caused by T. cruzi) and African sleeping sickness (caused by T. brucei and T. rhodesiense) have high morbidity and mortality in tropical and subtropical regions of America, Africa and Asia, which are classified by WHO as neglected diseases. Nowadays, the search for natural products as an alternative treatment has motivated the interest of the scientific community.

In the present investigation the antiprotozoal activity for nine aryl-substituted imidazoles was evaluated against promastigotes of $L$. amazonensis, one of the species involved in diffuse cutaneous leishmaniasis in South America [32]. Our interest was based on its in vitro action against amastigote from $L$. infantum reported in our previous work [15]. The results are summarized in Table 2 and the calculated $I_{50}$ is reported, as well as the $\mathrm{SI}$ for the $L$. amazonensis model based on the $\mathrm{CC}_{50}$ obtained on the mouse peritoneal macrophages (host cells) determined directly in the experiment.

According to the analysis of the results, all compound tested are less active than amphotericin B. Compounds 1, 2 and 7 showed a marked activity against promastigotes of $L$. amazonensis with $\mathrm{IC}_{50}=6.98 \pm 0.8$ $\mu \mathrm{M}, \mathrm{IC}_{50}=8.94 \pm 1.0 \mu \mathrm{M}$ and $6.72 \pm 0.6 \mu \mathrm{M}$, respectively (Table 2). It is also observed in Table 2 that compounds 1 and 7 have a high selectivity index, demonstrating the selective over promastigotes.

Table 1 shows how the imidazoles 1, 2, 3 and 4, which have a similar structure (differ only in position 2 of the imidazole ring), have very different $\mathrm{IC}_{50}$ values. Compound 1 is the one with the best antileishmanial activity against $L$. amazonensis $\left(\mathrm{IC}_{50}=6.98 \pm 0.8 \mu \mathrm{M}\right)$, while of the four the least active was compound $3\left(\mathrm{IC}_{50}=\right.$ $16.22 \pm 0.3 \mu \mathrm{M})$ and compounds 2 and 4 showed values of $8.94 \pm 1.0$ and $10.35 \pm 1.2 \mu \mathrm{M}$, respectively. These results demonstrate how the influence of the phenylp-dimethylamino (compound 1) and phenyl-p-hydroxyl (compound 2) group in position 2 of the imidazolic ring increases the inhibitor power of the imidazoles.

The order of activity is 7, 1, 2 and 4, the first three meet the $I C_{50} \leq 10 \mu \mathrm{M}$ criterion [33] to be considered as active compounds, although the last one is slightly higher. If Pink's criterion [34] is considered, these IC values should be between 2.3 and $2.4 \mu \mathrm{M}$. Therefore, it is recommended to continue its study due to the $\mathrm{SI}$ values and considering its toxicity. Taking these criteria

Table 2: Antileishmanial activity and cytotoxicity of aryl-substituted imidazoles.

\begin{tabular}{|l|l|l|l|l|}
\hline Compounds & $\begin{array}{l}\text { L. infantum }[1] \\
I C_{50} \pm S D(\mu \mathrm{M})\end{array}$ & $\begin{array}{l}\text { L. amazonensis } \\
I_{50} \pm S D(\mu \mathrm{M})\end{array}$ & $\begin{array}{l}\text { BALB/c mice } \\
\text { Macrophages } \\
C_{50} \pm S D(\mu M)\end{array}$ & SI \\
\hline $\mathbf{1}$ & $1.02 \pm 0.02$ & $6.98 \pm 0.8$ & $178.09 \pm 3.5$ & 26 \\
\hline $\mathbf{2}$ & $>64.0$ & $8.94 \pm 1.0$ & $69.32 \pm 1.5$ & 8 \\
\hline $\mathbf{3}$ & - & $16.22 \pm 0.3$ & $126.07 \pm 5.2$ & 8 \\
\hline $\mathbf{4}$ & $10.23 \pm 1.16$ & $10.35 \pm 1.2$ & $178.27 \pm 0.9$ & 17 \\
\hline $\mathbf{5}$ & $4.11 \pm 0.51$ & $15.94 \pm 2.4$ & $11.90 \pm 0.8$ & 1 \\
\hline $\mathbf{6}$ & $1.99 \pm 0.19$ & $>46.35$ & $41.48 \pm 0.5$ & 6 \\
\hline $\mathbf{7}$ & $40.89 \pm 6.21$ & $6.72 \pm 0.6$ & $31.48 \pm 0.6$ & 1 \\
\hline $\mathbf{8}$ & $16.44 \pm 1.77$ & $26.27 \pm 0.7$ & $25.63 \pm 0.4$ & 1 \\
\hline $\mathbf{9}$ & $4.07 \pm 0.42$ & $31.52 \pm 0.2$ & $6.16 \pm 0.5$ & 1 \\
\hline Ref. drug & $10.07 \pm 4.23$ & $0.03 \pm 0.006$ & 0.8 & 193 \\
\hline
\end{tabular}

$\mathrm{IC}_{50}$ : concentration of compound that caused $50 \%$ of inhibition growth; SD: Standard Deviation.

Ref. drug: Miltefosine for L. infantum; Amphotericin B for L. amazonensis [15]. 
Table 3: In silico molecular docking results against the enzyme selected.

\begin{tabular}{|c|c|c|c|c|c|c|}
\hline \multirow{3}{*}{ compounds } & \multicolumn{2}{|l|}{ 2JK6 } & \multicolumn{2}{|l|}{$1 \mathrm{~T} 5 \mathrm{~F}$} & \multicolumn{2}{|l|}{ 3NGU ${ }^{*}$} \\
\hline & \multicolumn{2}{|c|}{$\begin{array}{l}\text { Leishmania infantum } \\
\text { (Trypanothione Reductase) }\end{array}$} & \multicolumn{2}{|c|}{$\begin{array}{l}\text { Rattus norvegicus } \\
\text { (Arginase I) }\end{array}$} & \multicolumn{2}{|c|}{$\begin{array}{l}\text { Leishmania major } \\
\text { (NDKb) }\end{array}$} \\
\hline & $\Delta \mathrm{G}(\mathrm{kcal} / \mathrm{mol})$ & Ki (nM) & $\Delta \mathrm{G}(\mathrm{kcal} / \mathrm{mol})$ & $\mathrm{Ki}(\mathrm{nM})$ & $\Delta \mathrm{G}(\mathrm{kcal} / \mathrm{mol})$ & $\mathrm{Ki}(\mathrm{nM})$ \\
\hline 1 & -10.06 & 42.45 & -8.68 & 433.09 & -10.33 & 26.82 \\
\hline 2 & -10.1 & 39.77 & -9.55 & 99.7 & -9.57 & 97.18 \\
\hline 3 & -10.53 & 19.20 & -10.28 & 29.14 & -10.12 & 38.43 \\
\hline 4 & -10.32 & 27.37 & -9.33 & 143.84 & -9.67 & 81.25 \\
\hline 5 & -9.81 & 63.93 & -7.2 & $5.24^{*}$ & -9.23 & 172.09 \\
\hline 6 & -9.36 & 136.91 & -8.7 & 417.14 & -9.24 & 169.05 \\
\hline 7 & -9.25 & 165.99 & -8.96 & 269.45 & -8.98 & 262.16 \\
\hline 8 & -10.86 & 11.00 & -8.98 & 260.08 & -7.99 & $1.40^{*}$ \\
\hline 9 & -9.33 & 144.90 & -7.04 & $6.96^{*}$ & -9.27 & 160.23 \\
\hline Std-TryR & -11.30 & 5.19 & & & & \\
\hline Std-Argl & & & -6.32 & $23.38^{*}$ & & \\
\hline Std-NDKb & & & & & -9.03 & 238.87 \\
\hline
\end{tabular}

" $\mu M$ value, Std-TryR: ZINC12151998 [29], Std-Argl: Compound 30 [30], Std-NDKb: SU11652 [31]

into account, the imidazoles with the greatest potential to continue their studies are 1 and 4 , since compound 7 is not favored by its greater activity due to its low selectivity index and its greater toxicity.

Compounds 1, 5 and 9 have in common the phenyl-pdimethyl aminobenzaldeyde group as a substituent in the position 2 of the imidazole ring with very diverse activities, note how compound 9, which is a tri-aryl-imidazole, is inactive. The incorporation of an aryl substituent group in position 1 (tetra-aryl-imidazole) favors the activity, reaching the established activity criteria only for compound 1 with the benzimidazole substituent.

In the case of compounds 6 and 7, with structures much more similar to each other, they show a notable difference in activity. Both compounds possess the p-nitrophenyl substituent at the 2-position of the imidazole ring and differ in the position of the methyl group from the methylphenyl substituent at the 1-position of the imidazole ring (compound $6 \mathrm{~m}-\mathrm{CH}_{3}$ and compound $\left.7 p-\mathrm{CH}_{3}\right)$. Compound 7 is active while 6 is not active against $L$. amazonensis. However, in the previous study with $L$. infantum the result is inverse [15]. As shown in Table 2, there is a marked difference between the $\mathrm{IC}_{50}$ values determined against $L$. infantum and $L$. amazonensis, maintaining the same behavior only for compound 4 with similar $\mathrm{IC}_{50}$ values, so we can affirm that this behavior is due to the fact that the activities against both parasites were determined in different extracellular (promastigotes) and intracellular (amastigotes) forms.In addition, other recent studies reported by Martin, et al. [14] demonstrated the potential of imidazole in salts form as antileishmanial agents against promastigotes of $L$. amazonensis.

\section{Molecular docking studies}

Molecular docking is a computational tool employed in the design and discovery of novel drug candidates, and was applied in order to understand the binding interactions of aryl-substituted imidazoles with the three selected targets: Arginase I, Trypanothione Reductase and Nucleoside diphosphate kinase $b$. The binding affinity of the docked molecules was evaluated by binding energy, calculated inhibition constants ( $\mathrm{Ki}$ calc. by AutoDock 4.2), and hydrogen bonds in addition to the hydrophobic interactions with the enzyme pocket. The docked poses for each of the compounds have been evaluated and the pose with the lowest binding free energy and inhibition constant was thereby chosen (Table 3).

Potential Trypanothione Reductase protein (TyrR) inhibitors: Based on our docking analysis, potential candidates that inhibit TryR are listed in the first column of Table 3, the binding energy $(\Delta G)$ and inhibition constant (Ki) of the control inhibitor Std-TryR were found to be $-11.30 \mathrm{kcal} / \mathrm{mol}$ and $5.19 \mathrm{nM}$, respectively. However, the value for almost all aryl-substituted imidazoles is similar to $S t d-\operatorname{Try} R$, with $\Delta \mathrm{G}$ values between -9.33 and -10.86 $\mathrm{kcal} / \mathrm{mol}$ and $\mathrm{Ki}$ values in the order of $\mathrm{nM}$. Compound 8 shows the best value for $\Delta \mathrm{G}=-10.86 \mathrm{kcal} / \mathrm{mol}$ with a $\mathrm{Ki}=$ $11.00 \mathrm{nM}$ and has a similar conformation as the control drug when binding to TryR (Figure 3). Other ligands as compound 3 and 4 , showed also strong binding values of $\Delta \mathrm{G}=-10.53 \mathrm{kcal} / \mathrm{mol}(\mathrm{Ki}=19.20 \mathrm{nM})$ and $-10.32 \mathrm{kcal} /$ $\mathrm{mol}(\mathrm{Ki}=27.37 \mathrm{nM})$, respectively and those compouds have a similar binding conformation as compound 8 in the pocket of the enzyme TryR (Figure 4).

Three compound (3,4 and 8 ) showed similar 


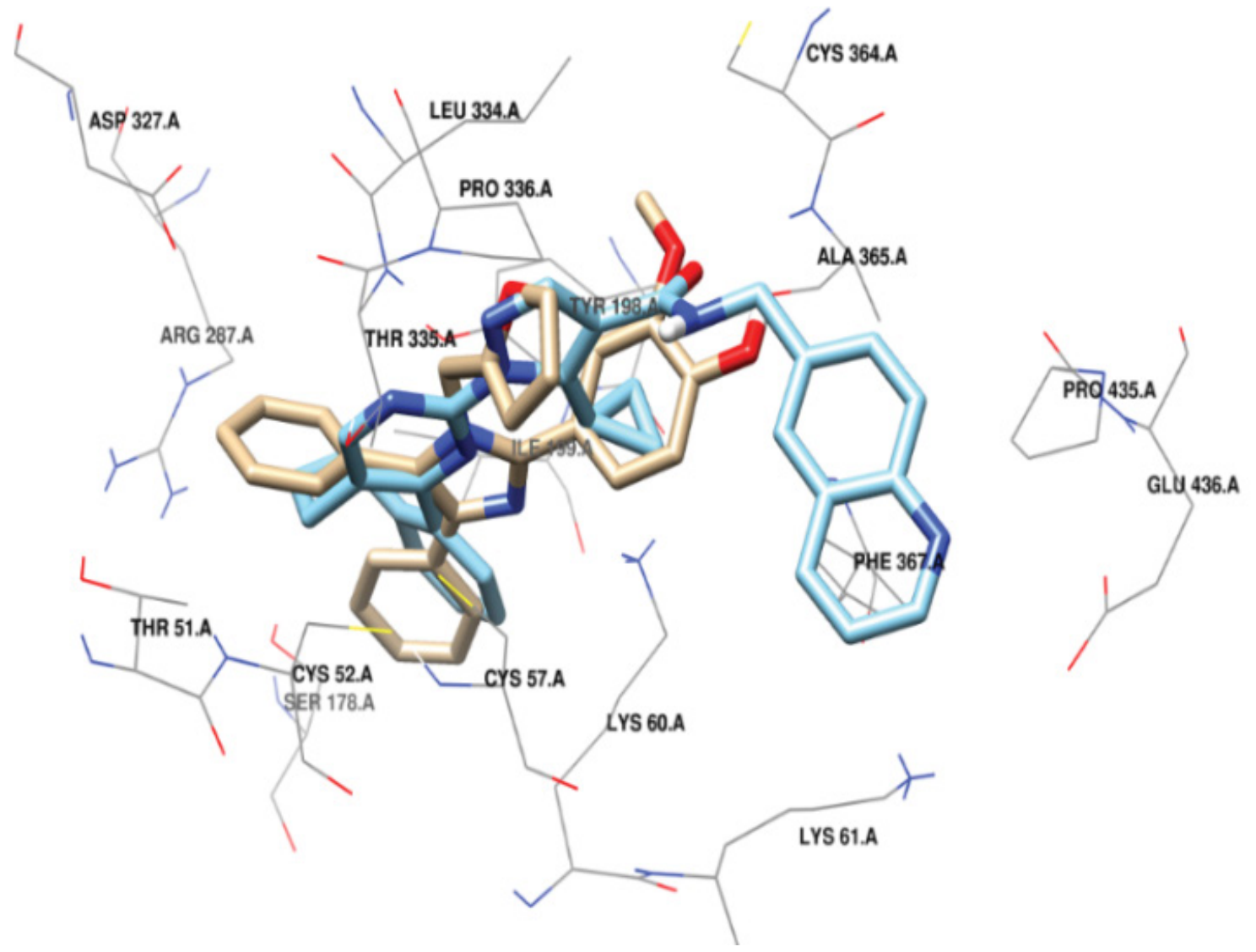

Figure 3: Superimposition of the best pose of compound 8 (tan) + Std-TryR (sky blue) included in the binding pocket of Trypanothione reductase.

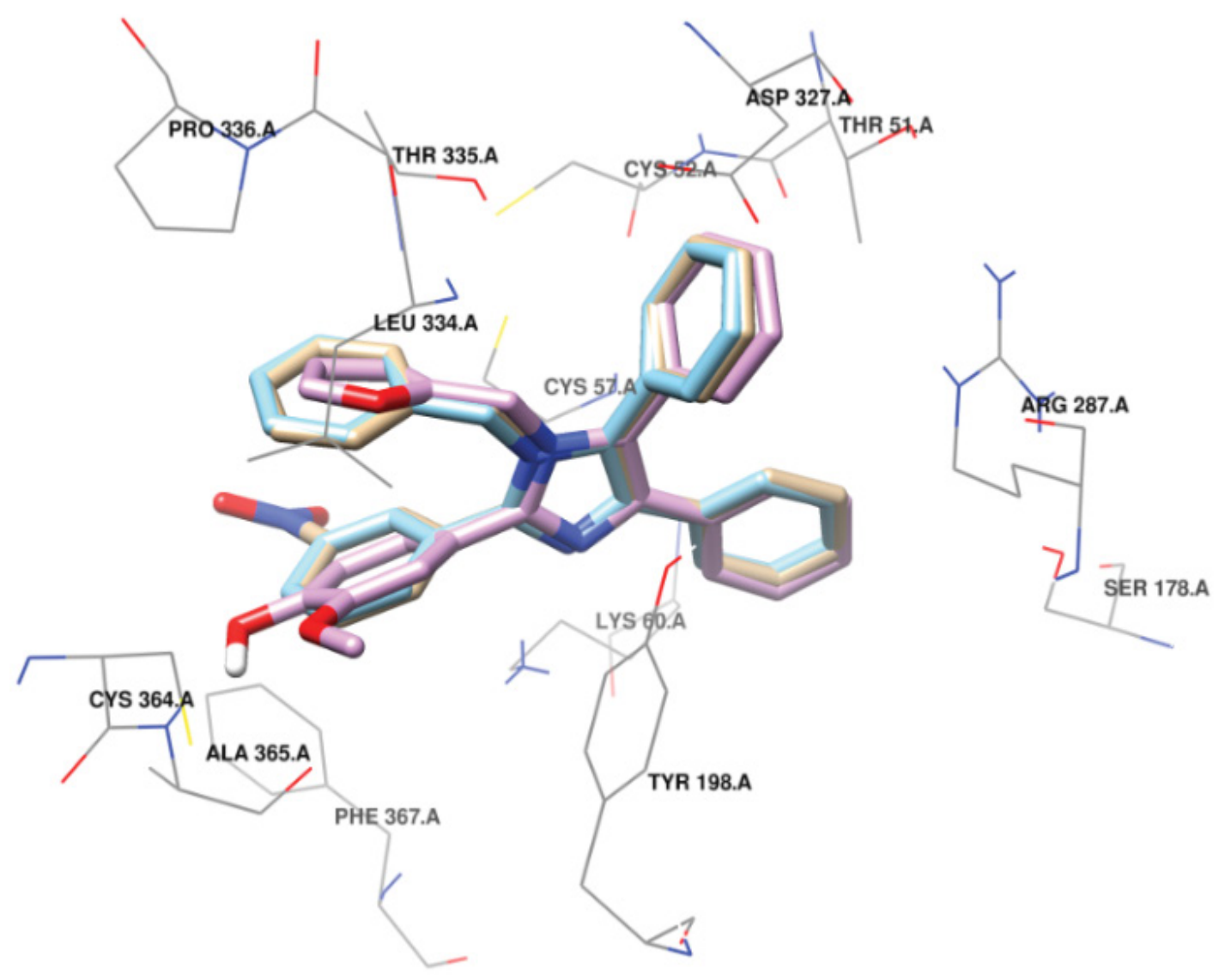

Figure 4: Superimposition of the best pose of compound 3 (tan) + compound 4 (sky blue) + compound 8 (orchid) included in the binding pocket of Trypanothione reductase. 
interaction in the binding pocket of TryR (Figure 5). Compound 3 was found to establish a hydrogen bond [N (pyridinic)....H-N] to the side chain of Lys 60 with a distance of $2.88 \AA$. The compound also shows hydrophobic interactions with Val55, Phe203, Gly56, Thr51, Leu334, Asp327, Leu334, Cys52, Pro336, Thr335, Tyr198, Cys57, Ala365 and Phe367 residues of this enzyme (Figure 5A). Compound 4 was bound in a hydrophobic pocket consisting of amino residues Ala365, Phe367, Cys57, Thr335, Pro336, Cys52, Asp327, Leu334, Thr51, Val55, Gly56 and Tyr198 and created one hydrogen bonding similar to compound 3 (with [N (pyridinic).... H-N] Lys60) (Figure 5C). Compound 8 interacted with Cys364, Leu334, Pro336, Thr335, Asp327, Thr51, Arg287, Cys52, Gly56, Val55, Phe203, Tyr198, Cys57, Phe367 by hydrophobic interaction. This

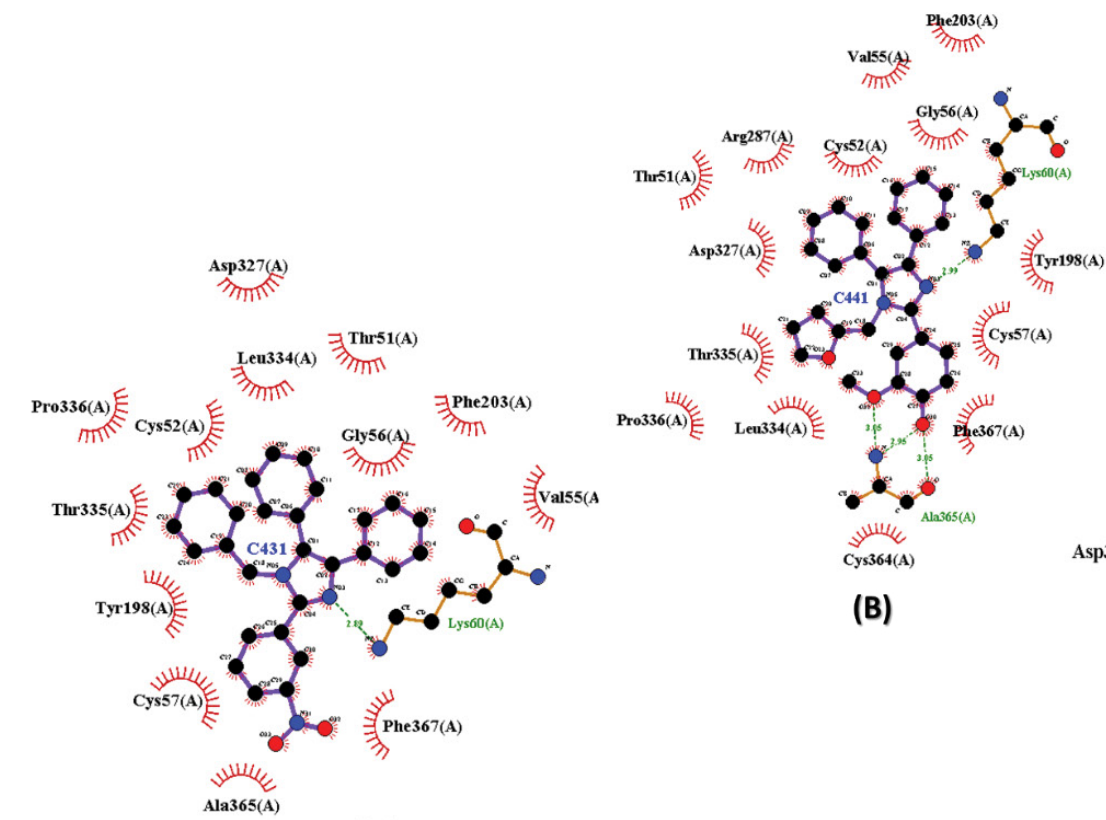

(A)

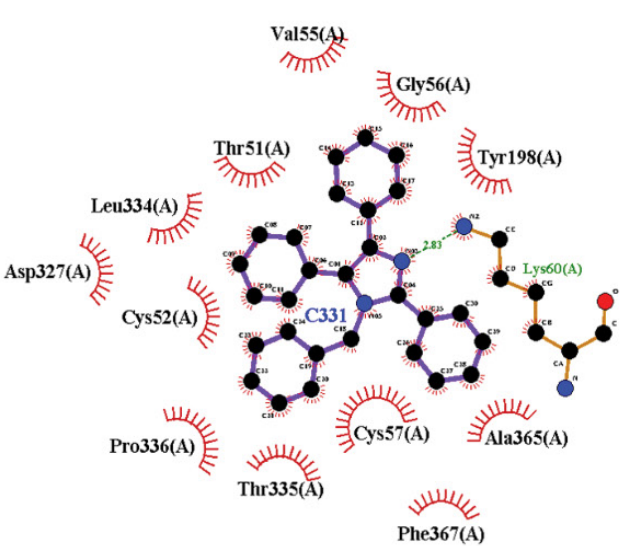

(C)

Figure 5: Docked structures of compounds A) 3, B) 8 and C) 4 in the Trypanothione reductase pocket represented using the LigPlot software [35].

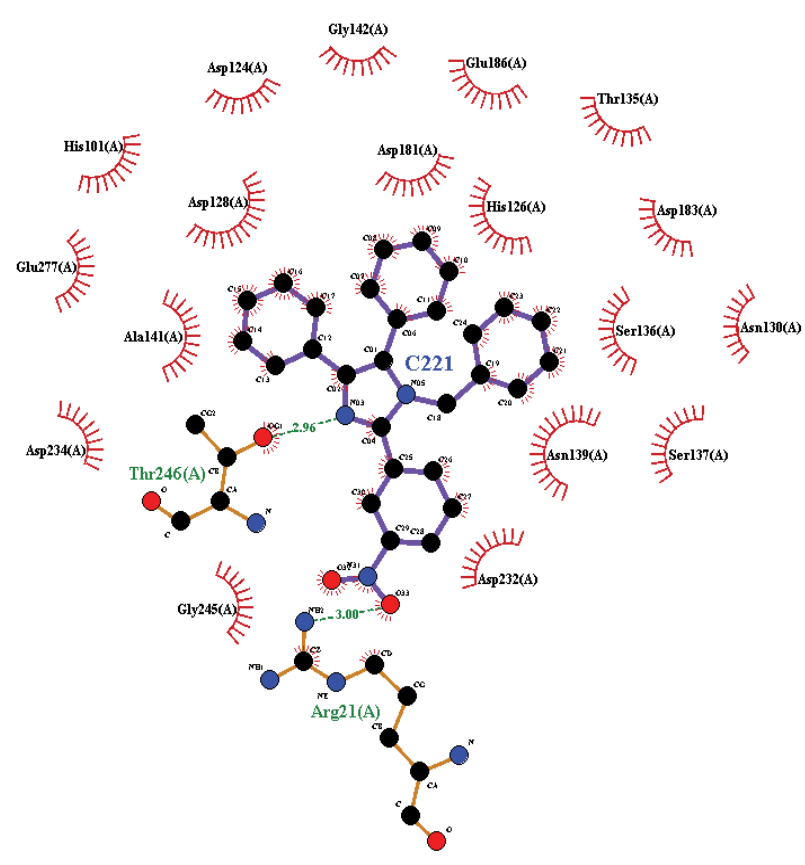

(A)

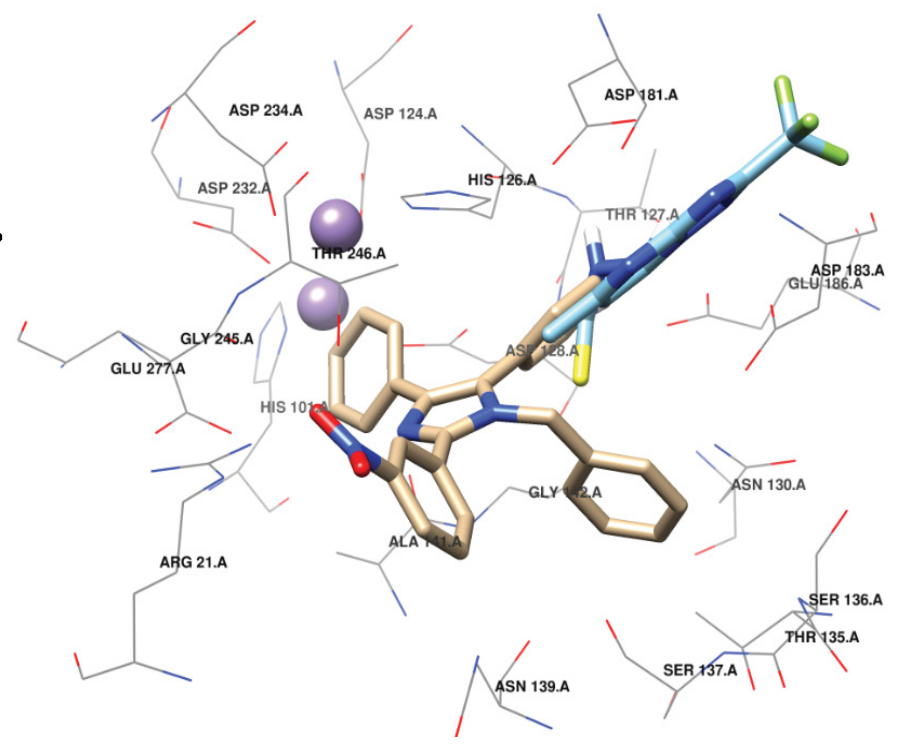

(B)

Figure 6: A) The interaction of compound 3 in the pocket of Arginase / using the LigPlot software [35]; B) Docked structures of compound 3 (tan) superimposed with Std-Argl (sky blue). 
compound establishes 2 hydrogen bonds with main chain $\mathrm{NH}$ and $\mathrm{CO}$ of Ala365 and [N (pyridinic).... H-N] to the side chain of Lys60 (Figure 5B).

Potential Arginase I protein (Argl) inhibitors: For the enzyme Argl with the control drug Std-Argl the binding energy was found to be $-6.32 \mathrm{kcal} / \mathrm{mol}$ with a $\mathrm{Ki}=23.38 \mu \mathrm{M}$. The values of $\mathrm{Std}-\mathrm{Arg} \mathrm{I}$ are exceded by all compounds (Table 3 ). The best ligand was 3 with $\Delta G=$ $-10.28 \mathrm{kcal} / \mathrm{mol}$ and $\mathrm{Ki}=29.14 \mathrm{nM}$ being better than Std-Argl. Also, the compounds 2 and 4 showed excellent values of $\Delta G$ with -9.55 and $-9.33 \mathrm{kcal} / \mathrm{mol}$ and an inhibition constant of 99.7 and $143.84 \mathrm{nM}$, respectively higher than Std-Argl.

Compound 3 showed hydrogen bonds [N(pyridinic)... .H-O] with Thr246 and [N(amine)....H-O] with Arg21 residue of $\mathrm{Arg} /$ (Figure $6 \mathrm{~A}$ ) and hydrophobic interactions with Gly245, Asp232, Asp234, Ala141, Glu277, Asp128, His101, Asp124, Gly142; His126, Glu186, His126, Thr135, Asp183, Ser136, Asn130, Asn139 and Ser137. Some of those residues Asp232, Glu277, Asp128, His101, Asp124, Glu186, His126, Asp183, Asn130 and Ser137 are involved in the active site according to reference [25]. We can see in Figure 6B the superimposition between compound 3 and Std-Argl. They share some important interacting residues as Asn130, Asp183, Asp128 and His126. Also, we can observe that compound 3 improves the interaction with the enzyme compared to Std-Argl.

Potential Nucleoside diphosphate kinase b protein (NDKb) inhibitors: Nucleoside diphosphate kinases $(N D K b)$ catalyze the transfer of a p-phosphoryl group from a nucleoside triphosphate (NTP) donor to a nucleoside diphosphate (NDP) acceptor in a reversible mechanism. Thus, NDKb are considered to participate in different metabolic pathways, such as the regulation of gene expresión in mammalian cells, bacterial pathogenesis and parasite housekeeping. For this reason, the NDKb are promising targets for the design and discovery of antiparasitic drugs, including anti-leishmanial agents.

Potential inhibitors of $N D K b$ are listed in the third column of Table 3 , the binding energies $(\Delta G)$ and inhibition constant (Ki) for the control drug Std-NDKb were found to be $-9.03 \mathrm{kcal} / \mathrm{mol}$ and $238.87 \mathrm{nM}$, respectively. However, all aryl-substituted imidazoles was found to be better binders than the reference compound Std-NDKb (except ligands 7 and 8), with $\Delta G$ values between -9.23 and $-10.33 \mathrm{kcal} / \mathrm{mol}$ and $\mathrm{Ki}$ values in the $\mathrm{nM}$ range.

Compound 1 was to be found the best ligand by this molecular docking study, with $\Delta G=-10.33 \mathrm{kcal} / \mathrm{mol}$ and $\mathrm{Ki}=26.82 \mathrm{nM}$, better than Std-NDKb. Compound 1 showed hydrophobic interactions with Tyr66,

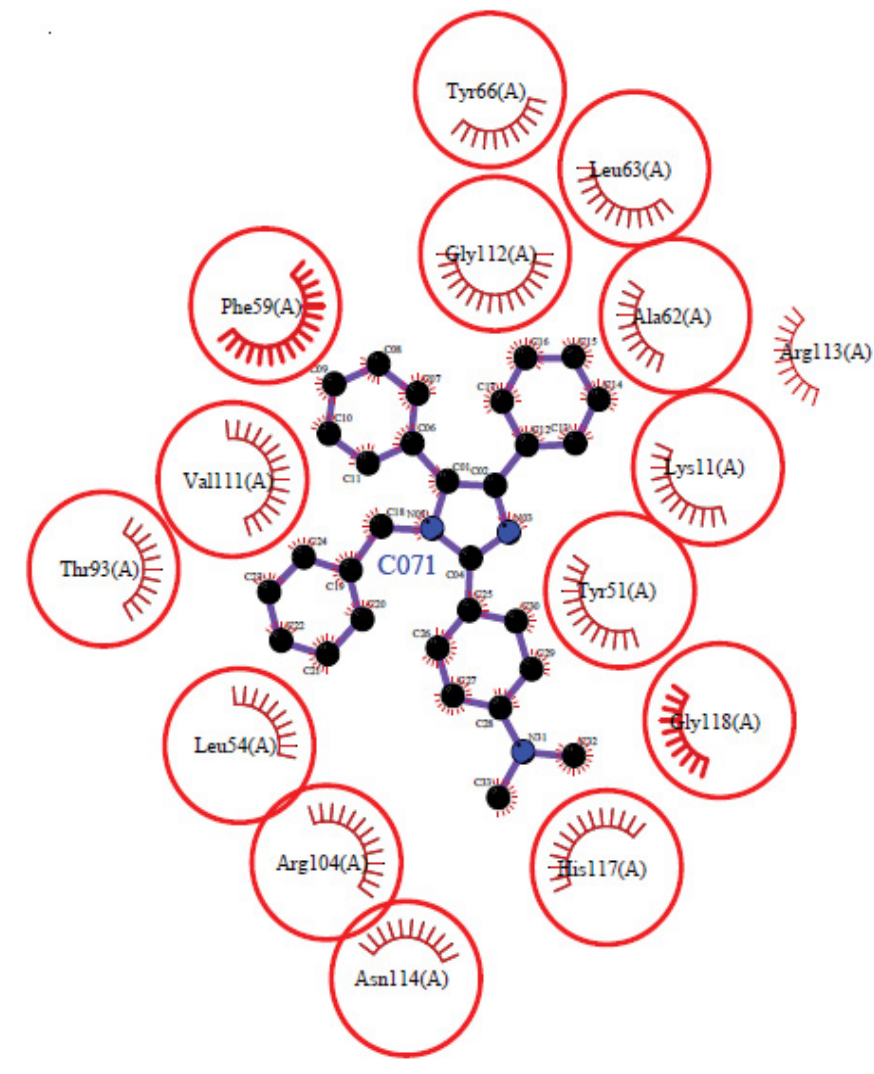

(A)

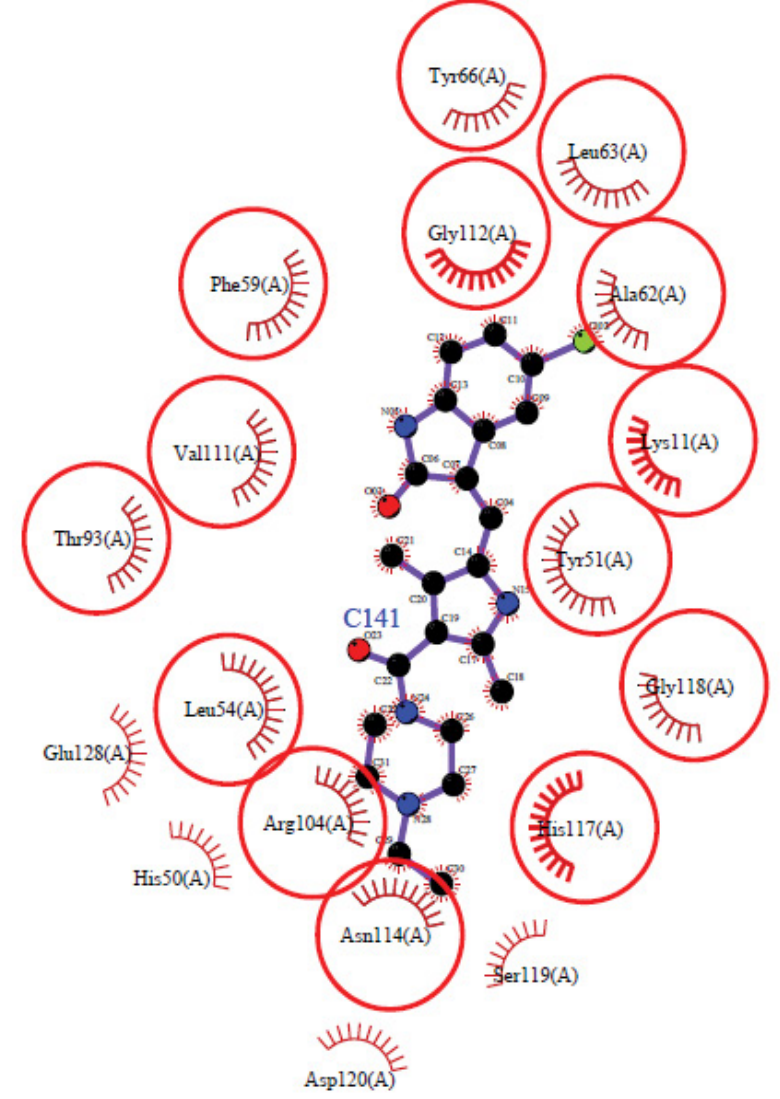

(B)

Figure 7: A) Interaction of compound 1 and B) Std-NDKb in the pocket of Nucleoside diphosphate kinase B) Represented using the LigPlot software [35]. 
Leu63, Gly112, Ala62, Phe59, Val111, Thr93, Leu54, Arg104, Asn114, His117 and Gly118. Comparing those interactions with the reference, compound 1 and StdNDKb share interactions with residues Tyr66, Leu63, Gly112, Phe59, Val111, Thr93, Leu54, Arg104 and Asn114 (residues whitin the red circles) involved in the active site [30-35] (Figure 7).

\section{Conclusions}

We identified the 4-(1-benzyl-4,5-diphenyl-1Himidazol-2-yl)-N,N-dimethylaniline (1) and1-benzyl2,4,5-triphenyl-1H-imidazole(4)as betterantileishmanial activity against $L$. amazonensispromastigotes with the best selectivity index and low toxicity between the nine aryl-substituted imidazoles studied. The main interactions, studied by molecular docking, are hydrophobic between the substituents in positions 1, 4, and 5 of the imidazolic rings and residues in the active site. The analysis permitted us to show the potential responsible target for the antileishmanial activity to be the Trypanothione Reductase protein. The reported results can partly justify and support the possible use of these imidazoles for the treatment of the leishmaniasis caused by the protozoa L. amazonensis.

\section{References}

1. World Health Organization (2021) Leishmaniasis.

2. Melby PC (2002) Recent developments in leishmaniasis. Curr Opin Infect Dis 15: 485-490,

3. Cos P, Janssens J, Piñón A, Cuesta-Rubio O, YglesiasRivera A, et al. (2018) Efficacy of four Solanum spp. extracts in an animal model of cutaneous leishmaniasis. Medicines 5: 49.

4. Waton NG (1956) Studies on mammalian histidine decarboxylase. Br J Pharmacol Chemother 11: 119-127.

5. Jin Z (2009) Muscarine, imidazole, oxazole and thiazole alkaloids. Nat Prod Rep 26: 382-445.

6. Antolini M, Bozzoli A, Ghiron C, Kennedy G, Rossi T, et al. (1999) Analogues of 4,5-bis(3,5-dichlorophenyl)-2trifluoromethyl-1H-imidazole as potential antibacterial agents. Bioorg Med Chem Lett 9: 1023-1028.

7. Lombardino JG, Wiseman EH (1974) Preparation and antiinflammatory activity of some nonacidic trisubstituted imidazoles. J Med Chem 17: 1182-1188.

8. Corell T, Hasselmann G (1983) Pharmacodynamics and toxicology of fenflumizole, a new non-steroidal antiinflammatory imidazole derivative. Acta Pharmacol Toxicol 53: 288-296.

9. Williams DR, Lee MR, Song YA, Ko SK, Kim GH, et al (2007) Synthetic small molecules that induce neurogenesis in skeletal muscle. J Am Chem Soc 129: 9258-9259.

10. Williams DR, Kim GH, Lee MR, Shin I (2008) Fluorescent high-throughput screening of chemical inducers of neuronal differentiation in skeletal muscle cells. Nat Protoc 3: 835839.

11. Rossi R, Ciofalo M (2019) Current advances in the synthesis and biological evaluation of pharmacologically relevant 1,2,4,5-tetrasubstituted-1H-imidazoles derivatives. Current Organic Chemistry 23: 2016-2101.
12. Pandey RK, Sharma D, Bhatt TK, Sundar S, Prajapati VK (2015) Developing imidazole analogues as potential inhibitor for Leishmania donovani trypanothione reductase: Virtual screening, molecular docking, dynamics and ADMET approach. J Biomol Struct Dyn 33: 2541-2553.

13. Srinivas N, Palne S, Nishi, Gupta S, Bhandari K (2009) Aryloxy cyclohexyl imidazoles: A novel class of antileishmanial agents. Bioorg Med Chem Lett 19: 324-327.

14. Martins RC, Dorneles GP, Teixeira VON, Antonello AM, Couto JL, et al. (2018) Imidazolium salts as innovative agents against Leishmania amazonensis. Int Immunopharmacol 63: 101-109.

15. Rojas Vargas JA, García López A, Pérez Y, Cos $P$, Froeyen $M$ (2019) In vitro evaluation of aryl-substituted imidazoles derivatives as antiprotozoal agents and docking studies on sterol 14a-demethylase (CYP51) from Trypanosoma cruzi, Leishmania infantum, and Trypanosoma brucei. Parasitol Res 118: 1533-1548.

16. Gabla JJ, Mistry SR, Maheria KC (2017) An efficient green protocol for the synthesis of tetra-substituted imidazoles catalyzed by zeolite BEA: Effect of surface acidity and polarity of zeolite. Catal Sci Technol 7: 5154-5167.

17. Sladowski D, Steer SJ, Clothier RH, Balls M (1993) An improved MTT assay. J Immunol Methods 157: 203-207.

18. Nakamura CV, Santos AO, Vendrametto MC, Luize PS, Dias Filho BP, et al. (2006) Cortez DAG, Ueda-Nakamura, T. Antileishmanial activity of hydroalcoholic extract and fractions obtained from leaves of Piper regnellii (Miq.) C. DC. var. pallescens (C. DC.) Yunck. Braz J Pharmacogn. 16: 61-66.

19. Katsuno K, Burrows JN, Duncan K, Hooft van Huijsduijnen $\mathrm{R}$, Kaneko T, et al. (2015) Hit and lead criteria in drug discovery for infectious diseases of the developing world. Nat Rev Drug Discov 14: 751-758.

20. Caridha D, Vesely B, van Bocxlaer K, Arana B, Mowbray $\mathrm{CE}$, et al. (2019) Route map for the discovery and preclinical development of new drugs and treatments for cutaneous leishmaniasis. Int J Parasitol Drugs Drug Resist 11: 106-117.

21. Evans DA (2014) History of the Harvard ChemDraw Project. Angew Chem Int Ed Engl 53: 11140-11145.

22. Da Silva ER, Castilho TM, Pioker FC, de Paula Silva CHT, Floeter-Winter LM (2002) Genomic organisation and transcription characterisation of the gene encoding Leishmania (Leishmania) amazonensis arginase and its protein structure prediction. Int J Parasitol 32: 727-737.

23. Shin H, Cama E, Christianson DW (2004) Design of amino acid aldehydes as transition-state analogue inhibitors of arginase. J Am Chem Soc 126: 10278-10284.

24. Feitosa AO, Ferreira FJN, Brigido HPC, Bastos MLC, Carvalho JM, et al. (2019) Study on experimental leishmanicidal activity and in silico of cytochalasin B. J Braz Chem Soc 30: 592-596.

25. Vieira PS, Giuseppe PO, Murakami MT, Oliveira AHC (2015) Crystal structure and biophysical characterization of the nucleoside diphosphate kinase from Leishmania braziliensis. BMC Struct Biol 15: 2-12.

26. Morris GM, Goodsell DS, Halliday RS, Huey R, Hart WE, et al. (1998) Automated docking using lamarckian genetic algorithm and empirical binding free energy function. $J$ Comput Chem 19: 1639-1662.

27. Baiocco P, Colotti G, Franceschini S, llari A (2009) 
Molecular basis of antimony treatment in leishmaniasis. $J$ Med Chem 52: 2603-2612.

28. Souza TACB, Trindade DM, Tonoli CCC, Santos CR, Ward RJ, et al. (2011) Molecular adaptability of nucleoside diphosphate kinase b from trypanosomatid parasites: Stability, oligomerization and structural determinants of nucleotide binding. Mol BioSyst 7: 2189-2195.

29. Matadamas-Martínez F, Hernández-Campos A, TéllezValencia A, Vázquez-Raygoza A, Comparán-Alarcón S, et al. (2019) Leishmania mexicana trypanothione reductase inhibitors: Computational and biological studies. Molecules 24: 3216.

30. Da Silva ER, Boechat N, Pinheiro LCS, Bastos MM, Costa CCP, et al. (2015) Novel selective inhibitor of Leishmania (Leishmania) amazonensis arginase. Chem Biol Drug Des 86: 969-978.
31. Vieira PS, de Arruda Campos Brasil Souza T, Honorato RV, Zanphorlin LM, Severiano KU, et al. (2017) Pyrroleindolinone SU11652 targets the nucleoside diphosphate kinase from Leishmania parasites. Biochem Biophys Res Commun 488: 461-465.

32. Bailey MS, Lockwood DNJ (2007) Cutaneous leishmaniasis. Clin Dermatol 25: 203-211.

33. Cos P, Vlietinck AJ, Berghe DV, Maes L (2006) Antiinfective potential of natural products: How to develop a stronger in vitro 'proof-of concept'. J Ethnopharmacol 106: 290-302.

34. Pink R, Hudson A, Mouriés MA, Bendig M (2005) Opportunities and challenges in antiparasitic drug discovery. Nat Rev Drug Discov 4: 727-740.

35. Wallace AC, Laskowski RA, Thornton JM (1996) LIGPLOT: A program to generate schematic diagrams of proteinligand interactions. Protein Eng 8: 127-134. 